\title{
Choosing Work Group Members: Balancing Similarity, Competence, and Familiarity
}

\author{
Pamela J . Hinds \\ Stanford University \\ Kathleen M. Carley and David Krackhardt \\ Carnegie Mellon University \\ and \\ Doug Wholey \\ University of Minnesota
}

\begin{abstract}
This study explores one of the contributors to group composition-the basis on which people choose others with whom they want to work. We use a combined model to explore individual attributes, relational attributes, and previous structural ties as determinants of work partner choice. Four years of data from participants in 33 small project groups were collected, some of which reflects individual participant characteristics and some of which is social network data measuring the previous relationship between two participants. Our results suggest that when selecting future group members people are biased toward others of the same race, others who have a reputation for being competent and hard working, and others with whom they have developed strong working relationships in the past. These results suggest that people strive for predictability when choosing future work group members. $\odot 2000$ Academic Press
\end{abstract}

People often play either a direct or an indirect role in choosing their work partners. In volunteer organizations, people decide which group or committee to join. Academics decide who to collaborate with on research projects. And,

This work was supported, in part, by the National Science Foundation, IRI-9216760.

Address correspondence and reprint requests to Pamela J. Hinds, Department of Industrial Engineering and Engineering Management, Stanford University, Stanford, CA 94305-4024. E-mail: phinds@eland.stanford.edu. 
in business organizations, an increasing number of recruiting processes are partially composed of evaluations by prospective peers. In a recent review of the diversity literature, Williams and O'Reilly (1998) observed that an important unanswered question in diversity research concerns what drives the composition of groups. Given the importance of group composition to group structure, performance, and satisfaction (see Moreland \& Levine, 1994, for a review), understanding the way that people choose their group members is a crucial step in understanding what leads to the creation of successful groups. In this study, we explore one of the antecedents to group composition-the basis on which people choose group members. Although preferences for working with others may evolve over time, there is often a point at which a person must make an explicit choice. By focusing on this explicit choice, we hope to provide valuable insight into how people use previous experience as input to the composition of future work groups.

Wehave used social psychological and sociological theories predicting interaction choice as well as social network theories to investigate how people choose work group members. To date, much of the research on interaction choice has focused on social relationships such as friendship (e.g., Carley \& Krackhardt, 1996; Festinger, 1954; Lazarsfeld \& Merton, 1954) and has neglected instrumental relationships such as work ties. Although friendships and informal ties have been identified as important relations in organizations (e.g., Brass \& Burkhardt, 1992; Krackhardt, 1992), formal work relationships al so are critical to the accomplishment of organizational goals. We explore how individual attributes, relational attributes, and previous network ties affect the choice of future group members. Welook at stated preferences for future group members rather than inferring choice based on existing group composition or changes in interaction within existing groups. This approach isolates the choice process by excluding other social and organizational pressures that influence the composition of teams.

\section{THEORY}

Organizations are deliberately constructed to achieve specific goals (Etzioni, 1964). But, rampant uncertainty in organizational life often threatens the achievement of the organization's objectives (Thompson, 1967). A prevalent theme in organizational research is the reduction of uncertainty as a way of regaining control over the fate of the organization (Thompson, 1967). Kanter (1977, chap. 3) observed that this need to limit uncertainty results in a drive to control and limit participation in both work and friendship networks. We suggest that this need to gain control by reducing uncertainty is al so operating at the individual level. Thus, in putting together project teams and work groups, individuals will, when given the chance, construct the group that they feel is most likely to succeed. Further, they will do this by choosing as cogroup members those whom they feel have a higher probability of producing a positive payoff. This suggests that workers will decide who they want to work with in the future based on those characteristics that create the most confidence in 
the other's ability to be a "good" group member. Such a process can be seen as one of social exchange in which partners conduct (consciously or unconsciously) a cost- benefit analysis weighting the potential contributions of the prospective group member as well as the potential costs (e.g., Blau, 1964; Thibaut \& Kelley, 1959).

But, what are these characteristics or indicators that could increase or decrease one's confidence in another's ability to contribute to a group and hence increase the likelihood that the group will succeed? Theories on friendship, group formation, and network evolution all suggest ways in which confidence in a positive work relationship might be achieved. Various scholars have argued that similarity and affect (e.g., Carley, 1991, 1999; Lazarsfeld \& Merton, 1954; Lott \& Lott, 1964), competence (e.g., Thibaut \& Kelley, 1959), and familiarity (e.g., Zander \& Havelin, 1960) increase people's preference to interact and work with one another. Others have argued for the importance of individual indicators of competence such as status (Berger, Wagner, \& Zelditch, 1985) and values congruence (Cable $\&$ J udge, 1996). In this paper, we attempt to explore concurrently the impact of individual attributes and previous work relationships on the choice of future group members. We consider the relative contributions of three uncertainty reduction mechanisms-homophily (similarity), reputation for competence, and familiarity-in predicting group member choice. Each of these factors has been extensively explored in the literature. But, most of this work examines a single factor at a time (homophily, familiarity, etc.). In the study reported here, we build on and integrate existing research by simultaneously tapping all three factors and using multiple indicators for each of these factors. This allows us to examine the relative contributions of each factor and build an integrated model depicting the basis on which work group members are chosen.

Homophily

Lazarsfeld and Merton (1954) coined the term "homophily" to refer to a tendency for people to be attracted to others who have similar attitudes, beli iefs, and personal characteristics. Similar people want to interact with one another and join the same groups, and they tend to value each other's contribution more than contributions from dissimilar people (see Lincoln \& Miller, 1979; Miller \& Smith-Lovin, 1987; Tsui \& O'Reilly, 1989). In fact, the relationship between homophily and affect is one of the most consistent findings in interpersonal research (see Lott \& Lott, 1965, for a review). One of the explanations for this phenomenon is that people with similar demographic backgrounds have more "language compatibility" than do those who are dissimilar (March \& Simon, 1958, p. 67). Others have argued that common knowledge or shared mental models may produce more opportunities for interaction (Carley, 1990, 1991; Kaufer \& Carley, 1993). In their review of the diversity literature, Williams and O'Reilly (1998) observed that similarity can result in more frequent communication, more positive attitudes, and decreased turnover in organizations. Further, demographic homophily fosters trust and reciprocity and enhances instrumental relations (Lincoln \& Miller, 1979). For a variety of reasons, 
homophily increases the ease of communication and improves the predictability of behaviors and values. Ther efore, when choosing group members, we expect people to favor peers who are similar to themselves as a means of increasing predictability within the group.

\section{H1. People will choose to work with others who are similar to themselves.}

Project groups, however, do not just come together for social reasons. They come together to do a particular task. To successfully complete a task the group will undoubtedly need a particular set of skills. As individuals work together they become aware of both the similar and the complementary skills of other group members. Groups with complementary skills can cover a wider range of possible problems and may bring a host of alternative information, thus increasing the overall knowledge and information processing capability of the group, which should in turn lead to higher group performance (Hollenbeck, Ilgen, Sego, Hedlund, Major, \& Phillips, 1995; see also J ehn, Northcraft, \& Neale, 1997, and Pelled, Eisenhardt, \& Xin, 1997). Groups with complementary skills should therefore be more successful to the extent that their skills are necessary to the task. To increase the likelihood that the group will succeed and the probability that a potential group member will provide value to the team, people should use skill complementarity as a factor in choosing work group members. In other words, individuals may trade some certainty in communicative and individual performance predictability for certainty in skill coverage. Thus, in terms of choosing future group members there might be both a general homophily effect (i.e., for demographic factors) and a contradictory complementarity effect for skills.

H2. People will choose to work with others who have skills complementing their own.

\section{Reputation for Competence}

Choosing a member of a work group can be viewed as an organizational decision like any other resource allocation or technical decision. Within the context of resource allocation, Pfeffer, Salancik, and Leblebici (1976, p. 228) introduced the universalism-particularism dimension of organizational decision making. Particularistic criteria are those that depend on the relationships between organizational members (e.g., homophily). Universalistic criteria are independent of therelationship between people. For example, individual competence to perform a job is a universalistic criterion. In instrumental groups, we predict that use of particularistic criteria will be complemented by universalistic criteria in the service of group goals.

As another means of reducing uncertainly, weexpect peoplewill usea person's ability to contribute to the task as a criterion when choosing group members. Some research supports the idea that people will choose others to work with based on the extent to which they can be expected to contribute to the group goal or task (Ridgeway, 1984; Thi baut \& Kelley, 1959). Other research suggests 
that people may fall back on more particularistic indicators such as familiarity because competence is too difficult to judge (Perrow, 1972, p. 11). Although assessment is difficult, we believe that people may not be willing to forgo this vital information about individual competence. Instead, they will gather information on individuals' competence through their interaction with others in the organization. Reputations then form as people search for indicators as to others' abilities and signal their own competence by alerting others to organizational accomplishments (Kilduff \& Krackhardt, 1994; Spence, 1973). We argue that reputational information about the abilities and work habits of people filters into the organization and generates reputations for competence. Although performance reviews, examinations, peer evaluations, and such are deemed "private" information, we believe that enough of this information seeps into the organization to create relatively accurate reputations reflecting the competence of organizational members.

One indication of the competence of potential group members is whether or not they have the skills required for successful completion of the project. For instance, in a project group chartered to write a computer program, the ability to program may be highly desirable. Although objective measures of individual capabilities are generally not shared and are difficult to judge, we argue that people rely on relevant information that flows over the organizational grapevine and thus make choices based on the relevant skills of their peers in the organization.

H3. People will choose to work with others who have instrumental skills that are relevant to the group task.

\section{Familiarity}

Another method of reducing uncertainty is to work with those whose personalities and work practices are familiar. Extensive research demonstrates that people who interact with one another are more likely to be positively disposed toward one another (e.g., Byrne, 1961; Festinger, 1953; Zander \& Havelin, 1960). Even groups of strangers express a preference to work with one another once they interact (Zander \& Havelin, 1960). In work situations, there are several ways in which familiarity reduces uncertainty. First, there is an expectation that the person's behavior will be similar in future interactions regardless of whether the prior interaction was positive or negative (see Rhodes, Newman, \& Ruble, 1990). Second, each time new members are added to a group, those members need to be "brought up to speed" and socialized to the group's work processes. When unfamiliar members are added to a group, coordination losses are incurred (Goodman \& Leyden, 1991). Without any personal experience with another individual, it is difficult to anticipate the extent to which new work practices will need to be negotiated and therefore the magnitude of the coordination losses. Because of theincreased predictability in behavior and coordination costs, we expect people who have worked together to choose to work together in subsequent groups. 
Of course, there are many cases where people have had negative experiences with their group members. Because the objective is to maximize the likelihood that the group will achieve its instrumental goals, it follows that people will only choose to work with peers with whom their previous relationship has been positive. In fact, previous research found that people in more successful groups prefer to work with others in that group more often than do those in less successful groups (Zander \& Havelin, 1960).

H4. People will choose to work with others with whom they have worked with in the past, particularly if the relationship resulted in a successful outcome.

\section{METHOD}

\section{Overview}

The data come from 33 software development groups with three to seven members collected over four years. Group members were undergraduates in an information systems (IS) major at Carnegie Mellon University. In their junior year, they were required to work in an assigned group for 4 months with the goal of developing a computer-based information system (project 1). During their senior year, all students were required to work on a different project with a different group (project 2). The purposes of the group projects in the curriculum are to help students learn to apply their knowledge and skills and to provide conditions for actively acquiring teamwork skills.

The junior project groups were ongoing, bounded groups with shared responsibility for their group performance. Group success was evaluated primarily by comprehensive grading criteria for the overall group project. In addition, group members' individual grades were adjusted based on confidential peer evaluations completed by group members at the end of the term.

Groups in the junior year were disbanded and assigned to new groups in the senior year. At the end of the junior year, students were asked to nominate peers with whom they would like to work on project 2 in their senior year. These choices were important because the instructors used them to assign students to groups for project 2 . We study the determinants of these choices for who one wants to work with in project 2.

\section{Data Collection Procedure}

We collected data from four main sources. (1) Surveys of perceptions of group process. Group members individually and privately completed three surveys of group behavior during project 1 at 1,2 , and 3 months into the project. (2) Weekly time reports. On a weekly basis, group members reported the hours they spent on project 1 . Time reports had to be signed by the group manager to verify accuracy of the reports. (3) External sources. Theseincluded demographic information, overall grade point average, and grades in other relevant courses. These data were taken from student records. (4). Per nomination survey. Four 
months following the completion of project 1 , students were asked to nominate up to five peers with whom they wanted to work on project 2 the following semester. Students were assured that nominations were confidential and would be used as input to form groups for the following term.

\section{Measures}

The data collected in this study are predominantly dyadic; that is, they reflect a relationship between two individuals. Dyadic data allows us to directly examine who chooses whom. It also allows us to explore how the nature of previous relationships leads to future relationships. To examine choice, dyadic matrices were created for most of our independent variables and for the dependent variable in the study. The matrices reflect i's relationship to $j$ in all cases.

Dependent variable: Group member choi cematrix. Each student in the program filled out a survey during the spring semester (approximately 4 months after the completion of project 1 ). In this survey, they were asked to name up to five of their peers that they wanted to work with on project 2 another 4 months hence. Each student made this choiceat only one point in time. Students were assured that their choices would be honored to the extent possible given the goals of the course. These data were then coded into a choice matrix which represented whether or not person $i$ indicated that he wanted to work with person $\mathrm{j}$ in the subsequent year. Each row in the dependent variable matrix therefore represented those people chosen by person i with a " 1 " and those people not chosen by person i with a " 0 ". Similarly, each column in the matrix reflected who specifically requested to work with person $\mathrm{j}$ and who did not identify person $\mathrm{j}$ as a preferred group member.

Independent variables: Homophily matrices. Previous studies exploring homophily and attraction have examined similarity in gender, race, ethnicity, tenure, age, education, and a variety of other demographic measures. In our setting, the subjects all have the same tenure in the organization (college juniors), areapproximately the sameage, and have essentially the sameeducational background. According to McPherson and Smith-L ovin (1987), our groups have a high level of induced homophily - that is, their options of interacting with dissimilar people are limited because of the built-in homophily within the organization. We therefore focused on gender, race, and role in our homophily measures. Data on gender and race were collected from student records. Two homophily matrices were then created in which a 1 indicates that the two subjects are the same on that dimension and a 0 indicates that they are different. Therefore, both rows and columns in the "same gender" matrix have 1's for every dyad of the same gender. In the race data, subjects were identified as Black, Asian, or White. The rows and columns in the "same race" matrix reflect whether or not the two people are the same race.

Similarly, a dichotomous $(0,1)$ matrix reflects whether or not $i$ and $j$ performed the same role in the group during project 1 . Possible roles included manager, programmer, analyst, and documentor (technical writer). Participants were categorized based on the function in which they spent a majority 
of their time on project 1 . Those pairs who performed the same role in project 1 received a 1 in the cell corresponding to their relationship, and those who did not perform the same role received a 0 .

Independent variables: Reputation for competence. There are several measures of competence that we hypothesize have become shared information in the organization and have become reputational. We sel ected five measures that we believe most closely map to performance evaluations in other types of organizations-grade point average, two relevant course grades, effort, and project success.

In most traditional organizations, the boss evaluates the contribution of each of his subordinates. In a classroom setting, this role is played by the instructor. The instructor determines the extent to which the student's performance meets the standards set forth by the organization. Therefore, we choose overall grade point averageand individual coursegrades in an analysis courseand a database design course as external evaluations of competence. The grade point average (GPA) of $j$ should bein indication of $j$ 's overall intel ligence and ability to perform well in a college setting. The analysis course grade refers to the individual score on exams and homework in a course covering the analysis and design of software systems. The database course grade refers to the individual's performance in a database design and devel opment course. Skill in analysis, database design, and database development are critical for successful performance in project 1 and project 2 . Again, we are hypothesizing that good performance in these courses becomes socially shared information as people signal their own value and search for indications of others' competence. GPA, analysis course grade, and database course grade are treated as attributes (columns) of person j. GPA is a continuous variable with 4 representing an A average and 0 representing a failing average. The analysis course grade and the database course grade are 5-level variables with 4 representing the highest grade $(A)$ and 0 representing failure.

Wealso included a measure for how successful person j's group was for project 1. People who are members of successful groups may be seen as "basking-inreflected-glory" and therefore may be viewed positively regardless of their contribution to the group (Cialdini et al., 1976). Groups were ranked against one another based on their performance in project 1 . The rankings were generated by the instructor for the project course with input from clients for whom the projects were being developed. This variable was constructed as a rank variable in which higher values represented higher levels of success.

Finally, we included a measure for the amount of effort people put into project 1. Whereas competence is a critical indicator of performance capacity, effort is an indicator of the individual's willingness to apply that capacity. Further, the number of hours put in by a peer may be easier for observers to evaluate than skill level. An attribute measure was created by totaling the number of hours reported by $\mathrm{j}$ on the weekly time reports for project 1 .

Independent variables: Familiarity matrices. Familiarity is a structural variable reflecting the extent to which the structure of project 1 threw two 
people together. Historically, familiarity has been operationalized in a variety of ways, including opportunity to interact based on physical proximity (e.g., Festinger, 1953), shared knowledge about a work process (e.g., Goodman \& Leyden, 1991), and participation in the same group (e.g., Zander \& Havelin, 1960). In their review, Lott and Lott (1965) concluded that familiarity requires opportunity to observe behavior and actual interaction. In this study, we have two measures of structural familiarity-participation in the same group and amount of interaction during project 1 at the end of month 1 , month 2, and month 3. We also have a measure for group success as an indicator of the quality of the interaction.

People who were in the same group in project 1 were assumed to be familiar with each other. Project 1 was a four-month-long effort in which groups worked together extensively. Therefore, being in the same group meets Lott and Lott's criteria for being able to observe behavior. For the "same group" measure, a matrix was created that indicates whether or not two students occupied the samegroup in project 1 . I f they bel onged to the samegroup, thecell representing the relationship was filled in with a 1, and if they belonged to different groups, it was filled in with a 0.

We also used direct measures of interaction. Students were asked, at three points during project 1, to report for each other student in their group the extent to which the respondent was working with that other group member. Students rated their interaction with each member of their group using a scale of 0 to 5 with $0=$ did not interact and $5=$ worked with a lot. Matrices were then created for each of the three time periods. For example, the cell Worked With $_{\mathrm{ij}}(\mathrm{t})=5$ means that $\mathrm{i}$ perceives that he works with $\mathrm{j}$ at level 5 .

Our hypothesis $(\mathrm{H} 4)$ suggests that familiar people will only want to interact again if the previous interaction was rewarding. To test this, we created an interaction term in which we multiplied the "same group" variable with our measure of project success. From these data, an interaction matrix based on the group's overall success was created. If the two people were in the same group, their project rank occupied the cell for the dyad.

\section{Analysis}

In our analysis, we explored three nested models. The order of the models reflects the prominence of that category in the literature and the expected strength of each predictor within the model. ${ }^{1}$ We added the structural factors last to examine the additional contribution thesefactors provide to understanding team member choice. First, we examined the contribution of homophily to people's choice of group members. Homophily was selected first because it is

\footnotetext{
${ }^{1}$ We tried alternate orders for the models and the results were the same. In addition, we note that in general, for any QAP regression of the type that we did, the order of entry of variables will not make any difference in the size of the coefficients or their significance for any regression equation. For example, if you have a model $Y=X 1+X 2+X 3$, it will not matter whether $X 1$ is first, second, or third; the results of this equation will al ways be the same for $X 1$ (and the same is true for $\mathrm{X} 2$ and $\times 3$ ).
} 
one of the most robust findings in social psychology and should therefore have strong explanatory effects as a predictor (Lott \& Lott, 1965; McPherson \& Smith-Lovin, 1987). Second, we examined theeffect of competence. Competence was sel ected second because theory predicts that competence should be a strong individual-level predictor of team member choice for instrumental teams. Finally, we examined familiarity. Familiarity is the third category added to the model because we use network techniques to explore not only the familiarity between two people but also their relative familiarity within the larger organization. By looking at these relational factors, we hopeto contribute both a better understanding of the category of familiarity and a new analysis technique for the question of how people choose work group members.

As is common in performing network analysis, the dependent variable of interest to us is dyadic in form. The number of observations, then, is considerably larger than the number of people in the study; in the current case, the $\mathrm{N}$ people in each year creates $\mathrm{N}(\mathrm{N}-1)$ dyadic observations for that year. It has been long recognized that traditional statistical methods cannot be applied to such data because these $\mathrm{N}(\mathrm{N}-1)$ observations are not independent of one another (Laumann \& Pappi, 1976; Proctor, 1975; Schott, 1987). For example, in the current research, the interaction effect (reflecting the extent to which $i$ worked with $\mathrm{j}$ in project 1 ) includes a value for i's level of interaction with every other person in the class. But, some people are more gregarious than others and may havehigher scores, in general, than their peers. This systematic interdependence occurs because each of the row values is taken from the same source. Such row (or column) independence can bias OLS tests of significance (see K rackhardt, 1988). Indeed, even robust nonparametric tests such as bootstrapping and jackknifing are sensitive to this assumption of independence of observations.

Over the past decade, several attempts have been made to address this problem by modeling the type of dependence among observations that might occur in a given context (e.g., Kenny et al., 1996; Lincoln, 1984; Mizruchi \& Galaskiewicz, 1994; Wasserman \& Faust, 1994). These approaches work well if, in fact, the data conform to the model specifications. However, the number of parameters that could reasonably influence the dependence among these observations is far greater than the number of observations (Krackhardt, 1988), and thus no assurances can be made that the model is correctly specified.

\section{The QAP Test}

An alternative approach, however, was developed for bivariate cases by L. J . Hubert (1987) and was extended to multivariate cases by Krackhardt (1987, 1988). This approach, called the QAP (quadratic assignment procedure), has been shown to be robust against a wide array of sources of autocorrelation frequently assumed in dyadic network problems. For example, Krackhardt (1988) demonstrated that traditional tests of significancewill havea probability of greater than .5 of finding significant results in a sample drawn from a population where the null hypothesis is true even when the dyadic data are 
only moderately autocorrelated. He further demonstrated that QAP tests are robust against even extreme autocorrelation in the data. That is, even in these extreme cases, the multivariate QAP tests found significant results exactly an alpha portion of the time-which is exactly what one expects and demands of an unbiased significance test.

The QAP test is a simple two-step procedure. First, the data, originally in matrix form, are "vectorized" (strung out into a vector of observations) with a length $\mathrm{N}(\mathrm{N}-1)$, and an ordinary multiple regression is performed on them, resulting in a traditional beta coefficient estimated for each independent variable. These coefficients are unbiased even if the data are autocorrelated (J udge et al., 1990, p. 27). The problem, however, is that the traditional estimates of standard errors of these coefficients are very sensitive to autocorrelation in the data-hence they perform poorly as the basis of significance tests of these coefficients.

The second step in the QAP test, then, is to generate a null hypothesis reference distribution against which the observed coefficient can be compared to determine its statistical significance. This reference distribution is created by randomly permuting the dependent variable matrix multiple times, each time recalculating the regression coefficients for each independent variable predicting the permuted dependent variable. In our case, with 999 permutations, this would result in a set of 999 beta coefficients for each independent variable against which the observed beta could be compared. If the observed beta is larger than all 999 of the betas generated under the null hypothesis (represented by the randomly permuted data), then we say that that beta is significantly different from random at the .001 level (the exact $p$ value is calculated as $(S+1) /(K+1)$, where $S$ is the number of coefficients based on randomly permuted versions of the dependent variable that are greater than or equal to the observed coefficient and $K$ is the number of permutations performed).

The key to theQAP test is the exact nature of the permutation. The permutation is of a restricted form: All rows and columns of the matrix are permuted identically. That is, if row 3 and row 7 are switched, then columns 3 and 7 are switched in the same manner. This form of permutation is tantamount to a "relabeling" of the matrix (actors switch places) while the structure of the matrix remains unchanged under each permutation. Thus, to the extent that there is autocorrelation in the data, the autocorrelation is preserved under each permutation (as is the extent of collinearity among all independent variables). This leads to a conditional permutation test, where the null hypothesis reference distribution is based only on cases where the data are constrained by the same structural (row, column, and reciprocity) features as the observed data. It is the nature of this permutation that permits the test to be so robust against the kind of autocorrelation that is common in network data.

QAP was first suggested for the bivariate case by Hubert and others (Backer \& Hubert, 1981; Hubert \& Golledge, 1981; Hubert \& Shultz, 1976) and then adapted to test for spuriousness (Krackhardt, 1987) and to the case of multiple regression (Krackhardt, 1988). MRQAP (mutipleregression quadratic 
assignment procedure) (Krackhardt, 1998, 1993) is a straightforward extension of Hubert's (1987) bivariate permutation test. Hubert's test is appropriate for any problem that can be formulated as a correlation between two $\mathrm{N} \times \mathrm{N}$ Cartesian product matrices. Network data, such as we are using, are of this form. Krackhardt (1992) extended Hubert's procedure by adding pairwise reciprocity. The permutation version of MRQAP (Krackhardt, 1993), which we use in this paper, has several advantages over the analytic MRQAP procedure (Krackhardt, 1988). Among the advantages of the permutation approach are that it is somewhat less biased when there are many independent variables and it permits testing of the overall R-square and intercept against a random null hypothesis.

Krackhardt (1993) suggests the use of the multiple regression quadratic assignment procedure to deal with this problem of biased significance tests. In the MRQAP analysis, the dependent variable is an $\mathrm{N} \times \mathrm{N}$ matrix rather than a vector as is normally the case in regression analysis. The first step in the MRQAP procedure is to calculate the OLS estimates of the regression coefficients based on the $\mathrm{N}(\mathrm{N}-1)$ observations contained in the matrices (the diagonals are ignored). Then the rows and columns of the dependent variable matrix are permuted to give a new "random" matrix. The OLS regression is then repeated with this new permuted matrix, resulting in different beta coefficients. The procedure is repeated, resulting in a distribution of beta values based on these permuted matrices. This distribution of values becomes the reference distribution against which the observed coefficients are compared. If less than $5 \%$ of the betas for a given variable derived from the permuted regressions are larger than or equal to the observed beta for that variable, we say that the beta is significant at the .05 level (one-tailed). If less than $1 \%$ of the betas are larger than or equal to the observed beta, we say that the beta is significant at the .01 level.

The permutation based MRQAP procedure is illustrated in Carley and Krackhardt (1996). Since MRQAP is an OLS procedure, the first moments (the beta estimates) are unbiased estimates. Further, both the analytic and the permutation version of MRQAP are superior to OLS in testing thenull hypothesis (beta $=0$ ) for network data. In other words, such hypotheses tests are robust against the independence of observation problems one encounters in network data (Krackhardt, 1988). As noted by Carley and Krackhardt (1996), "an OLS test of regression coefficients for random network data drawn from a null population will reach the .05 level of significance more than half the time. In contrast, the MRQAP test of these same coefficients reaches the 05 level of significance about $5 \%$ of the time, as it should, independent of the extremity of the network autocorrelation in the data."

\section{The Meta Analysis}

Meta analysis allows one to combine the results from independent studies (samples) to make an overarching statement about the strength and significance of a hypothesized relationship. M eta analysis is commonly seen in reviews 
of an area where many published studies often use different measures and models but attempt to answer a similar question. The application of meta analysis in these cases has come under severecriticism because of many factors, such as the fact that dissimilar models are inappropriately combined and that relying on published studies underrepresents those research efforts that found no results (and thus were never published).

The current study, however, is a good example of how meta analysis can be usefully applied (Hedges \& Olkin, 1985). I dentical models and measures are used in each sample, and there is no selective sampling based on the results. However, the interpretation of a meta analytic result (both for the effect size and significance of the result) depends on the assumption that the samples (studies) are drawn from the same population, vis-a-vis the variables under consideration. Hedges and Olkin (1992) recommend performing a Q test across the samples or studies to determine whether they differ significantly on the variables of interest for the meta analysis. If the samples are not significantly different from each other in the $\mathrm{Q}$ test, then we can proceed with a metaanalytic test to see if the combined results are significant (as well as to calculate a combined effect size). If, on the other hand, the $\mathrm{Q}$ test indicates that the samples do differ significantly from each other, then it would be inappropriate to suggest that results of the meta-analysis indicate anything about a combined result (as opposed to merely different laws governing each sample separately).

According to Hedges and Olkin, the $\mathrm{Q}$ test must be precede any meta-analytic test. Of the four overall meta-analytic significance tests reviewed by Hedges and Olkin (1985), theStouffer test was onethat encounter ed the fewest difficulties and restrictions in interpretation and application. As such, they recommend the Stouffer test and we follow their recommendation in this paper.

However, performing a $Q$ test across our four samples poses a serious problem. The $Q$ test relies on estimates of the standard errors of the beta coefficients being tested. As noted earlier, traditional estimates of standard errors in dyadic data cases have the potential of being severely biased. Thus, we cannot employ a traditional Q test here. F aced with a similar dilemma, Krackhardt and Kilduff (1999) devel oped a Q test for dyadic data using the same logic as for QAP tests: They calculate pseudo-standard errors of the coefficients based on the random permutations of the data. Each of these estimates of standard errors, then, is conditioned on the structure and autocorrelation in the data, just as were the direct significance tests. We will use the same procedure Krackhardt and Kilduff developed here.

Specifically, a Q test is a three-step procedure. First, the pseudo-standard errors of each beta coefficient are calculated. Second, a weighted combined coefficient (effect size) is calculated, taking into account its pseudo-standard errors across the sites. Third, a Q test is performed to assess whether or not the sites could reasonably be expected to be drawn from the same population, given the standard errors estimated in step 1.

The calculation of the standard error of the beta coefficient was straightforward. For each given independent variable, a vector of beta coefficients of length 999 was created from the regression calculations generated from the 
999 permutations of the dependent variable under the null hypothesis. The standard deviation of this vector of randomly generated beta coefficients was used as the estimate of the standard error for that beta.

The weighted combined coefficient, termed "betaplus" by Hedges and Olkin (1985), is calculated as the weighted average of the coefficients observed across the four sites. The weight of each of the four site coefficients was the inverse of the square of the standard error of estimate for that beta at that site. This weighting schemegives priority to beta estimates with a smaller standard error.

The $\mathrm{Q}$ for each independent variable is calculated by summing the weighted squared differences between each site's beta estimate and the combined estimate, betaplus (see Krackhardt \& Kilduff, 1999, for a detailed example of these calculations). The weight for each term in this sum of squares is again the inverse of the square of the pseudo-standard error for that beta at that site. This $Q$ value is distributed as a chi square under the null hypothesis that all sites are drawn from the same population. The degrees of freedom for this $Q$ test is the number of terms in the calculation of $Q$ minus one (in the present case, that equals 4 sites $-1=3 \mathrm{D} 3$ degrees of freedom).

The Data

The data in this study are gathered from four distinct groups of students over four years. Each year was analyzed separately and a meta-analysis was performed to integrate the findings into a single measure (see Wolf, 1986). We used Stouffer's combined test (Stouffer, Suchman, DeVinney, Star, \& Williams, 1949) because of its straightforward calculations and its sensitivity to results in opposite directions, as well as because it has already been successfully applied to the meta-analysis of MRQAP results (see Krackhardt \& Kilduff, 1999). In Stouffer's test, p values from the regression analysis are converted into $z$ scores and summed over the tests performed. This sum is then divided by the square root of $\mathrm{N}$, where $\mathrm{N}$ equals the number of tests. We have reported the $z$ scores for the meta-analyses as "zmeta" in the text and tables to distinguish the meta-analyses tests from other statistical tests.

Prior to conducting the meta-analysis, we also generated a Q statistic for all variables within each model. The purpose of the $\mathrm{Q}$ statistic is to determine the extent to which the 4 years of data are likely to be drawn from one common population with regard to the particular variable being tested. A Q test for network data was developed by Krackhardt and Kilduff (1999) to address problems associated with autocorrelated data. The resulting Q statistic is asymptotically distributed as $\chi^{2}$ with ( $\left.k-1\right)$ degrees of freedom. A high Q statistic with a significant $p$ value suggests that the four years are not all drawn from the same population with regard to the particular variable. In other words, a significant Q statistic suggests that all four years did not behave in a consistent way, thus making interpretation of the meta-analysis difficult. The Q statistics (Q scores) are reported in the tables along with the zmeta. 
TABLE 1

Summary of Sample Characteristics for Each Year

\begin{tabular}{lcccc}
\hline & Year 1 & Year 2 & Year 3 & Year 4 \\
\hline Number of students & 38 & 40 & 45 & 42 \\
Mean group size & 3.80 & 5.71 & 5.62 & 5.25 \\
Number of groups & 10 & 7 & 8 & 8 \\
Percent female & 21.1 & 25.0 & 24.4 & 21.4 \\
Percent Nonwhite & 13.2 & 42.5 & 33.3 & 40.5 \\
Average GPA & 2.72 & 2.56 & 2.39 & 2.70 \\
\hline
\end{tabular}

\section{RESULTS}

Table 1 provides a summary of the composition of the sample during project 1 for each of the four years. As indicated in Table 1 , the mean group size ranged from 3.80 to 5.71 over the four years with 7 to 10 groups per class.

Between 21 and $25 \%$ of the students were female with no significant difference in percentage female from year to year, $\chi^{2}(3, N=165)=.285, p<.975$ The percentage of nonwhite students varied significantly over the four years, $\chi^{2}(3, \mathrm{~N}=165)=9.495, \mathrm{p}<.025$. This is largely accounted for by the small percentage of minorities during the first year as compared to later years. Students' average GPA over the four years ranged from 2.39 in year 3 to 2.72 in year 1.

To systematically test the hypotheses, nested regression models were calculated. Table 2 contains the multiple regression QAP model (model 1) for each year as well as the Q score and meta analysis (zmeta) for the four years. Model 1 tests our hypothesis that homophily will be a determinant of group member choice. The results show a strong and consistent preference for working with the people of the same race, betaplus $=.025$, zmeta $=3.82, p<.01$. In fact, all four years resulted in positive relationships between race and choice regardless of the percentage of nonwhite students in the course. In contrast, no particular preference was found for working with people of the same gender, betaplus $=-.004$, zmeta $=-.25, p<.41$. People's preference for choosing others with the same role on project 1 varied, with years 1,3 , and 4 resulting

\section{TABLE 2}

Multiple Regression QAP Predicting i's Choice of $\mathbf{j}$ as a Work Partner (Model 1 )

\begin{tabular}{lcccccccc}
\hline & Year 1 & Year 2 & Year 3 & Year 4 & \multicolumn{2}{c}{ Meta-analysis } \\
\cline { 7 - 9 } & $(\mathrm{N}=1406)$ & $(\mathrm{N}=1560)$ & $(\mathrm{N}=1980)$ & $(\mathrm{N}=1722)$ & Betaplus & Q score & Zmeta \\
\hline Homophily & & & & & & & & \\
Same gender & .015 & -.001 & -.009 & -.014 & -.004 & 1.74 & -0.25 \\
Same race & $.045^{*}$ & $.030^{*}$ & $.039^{* *}$ & .006 & .025 & 4.98 & $3.82^{* *}$ \\
Same role & .012 & -.025 & .022 & $.059 *$ & .025 & 4.33 & 1.19 \\
\hline
\end{tabular}

$* \mathrm{p}<.05$ (one-tailed).

$* * \mathrm{p}<.01$. 
in positive relationships and year 2 resulting in a negative relationship. Although the meta analysis is not significant, zmeta $=1.19, \mathrm{p}<.12$, the data are suggestive of a tendency to select others who occupy the same role, i.e., betaplus $=.025$. Our hypothesis $(\mathrm{H} 1)$ that people will prefer to work with similar others is somewhat supported by these analyses although preference for working with people of the same race is the only strong and consistent predictor of choice across the four years.

We argued in hypothesis 2 that people will choose team members who have complementary skills. Therefore, we expected people to choose others who had roles different than their own within the group. In model 1 , it can be seen that there was no consistent pattern of choosing team members with either the same or complementary roles in the previous project. Thus, hypothesis 2 was not supported.

In hypothesis 3, we argued that people want to work with others who have a reputation for being competent at relevant tasks. Table 3 contains a multiple regression QAP model (model 2) with both homophily and competence measures. This analysis clearly indicates that people prefer to work with others who have a reputation for being competent in domains relevant to the task. People consistently chose work group members who had good grades in the analysis and database courses, who put a great deal of effort into project 1 , and who were in successful groups for project 1 . Grade point average was not a predictor of group member choice, betaplus $=.010$, zmeta $=1.07, p<.15$, although the values were positive for each year. Grade point average is a broader measure of competence than performance in relevant courses and similar projects. These analyses suggest that overall intelligence and ability to succeed in college were weighted less heavily than skills specific to the task at hand. In addition to competence, being the same race continued to be a significant factor in group member choice, suggesting that people want to work with people who are competent but are also of the same race.

Our last model (model 3) is summarized in Table 4. In this model, we add our familiarity measures to both the homophily and competence measures. In hypothesis 4, we argued that people will choose group members with whom they have worked with in the past, particularly if the relationship has been successful. The results of model 3 provide partial support for hypothesis 4 . Although there is a significant positive correlation between being in the same group for project 1 and group member preferences for project 2 , zmeta $=5.68$, $p<.01$, the relationship is no longer significant when either the measure of the amount that i actually worked with $\mathrm{j}$ or the interaction term "success*same group" is added to the model. This suggests that just being in the same group is not enough to cause people to want to work together again. In the combined model, measures of interaction between $\mathrm{i}$ and $\mathrm{j}$ are significantly positive at all three time periods. F or months 2 and 3 the data are consistently positive across all four years. The data for month 1 is less consistent, with year 2 resulting in a negative relationship. In fact, the Q score associated with working relationship during month 1 is too high to allow interpretation of the meta analysis with confidence. Still, taken together, these analyses suggest that people want 
TABLE 3

Multiple Regression QAP Predicting i's Choice of $\mathbf{j}$ as a Work Partner (Model 2)

\begin{tabular}{|c|c|c|c|c|c|c|c|}
\hline & \multirow{2}{*}{$\begin{array}{c}\text { Year } 1 \\
(\mathrm{~N}=1147)\end{array}$} & \multirow{2}{*}{$\begin{array}{c}\text { Year } 2 \\
(\mathrm{~N}=1482)\end{array}$} & \multirow{2}{*}{$\begin{array}{c}\text { Year } 3 \\
(\mathrm{~N}=1760)\end{array}$} & \multirow{2}{*}{$\begin{array}{c}\text { Year } 4 \\
(N=1640)\end{array}$} & \multicolumn{3}{|c|}{ Meta analysis } \\
\hline & & & & & Betaplus & Q score & Zmeta \\
\hline \multicolumn{8}{|l|}{ Homophily } \\
\hline Same gender & .031 & .004 & -.009 & $-.023 \dagger$ & -.002 & 4.56 & -.08 \\
\hline Same race & .039 & .019 & $.028 *$ & .007 & .021 & 2.06 & $2.83^{* *}$ \\
\hline Same role & .009 & -.026 & .030 & $.087 *$ & .032 & 7.45 & 1.27 \\
\hline \multicolumn{8}{|l|}{ Reputation for competence } \\
\hline Grade point average & $.013 \dagger$ & .014 & .006 & .012 & .010 & .15 & 1.07 \\
\hline Analysis course grade & $<.003^{*}$ & .013 & .020 & .012 & .014 & .92 & $1.91 *$ \\
\hline Database course grade & -.002 & .010 & $.018^{*}$ & $.018^{*}$ & .015 & 1.12 & $2.21 *$ \\
\hline Effort on project 1 & $<-.001$ & $<.001 \dagger$ & $<.001 *$ & $<.001^{*}$ & .000 & 1.90 & $2.63^{* *}$ \\
\hline Success of project 1 & .033 & .009 & .009 & $.103^{* *}$ & .023 & 4.49 & $2.19 *$ \\
\hline
\end{tabular}

$\dagger \mathrm{p}<.10$ (one-tailed).

$* p<.05$.

$* * \mathrm{p}<.01$. 
TABLE 4

Multiple Regression QAP Predicting i's Choice of $\mathbf{j}$ as a Work Partner (Model 3)

\begin{tabular}{|c|c|c|c|c|c|c|c|}
\hline & \multirow{2}{*}{$\begin{array}{c}\text { Year } 1 \\
(\mathrm{~N}=1147)\end{array}$} & \multirow{2}{*}{$\begin{array}{c}\text { Year } 2 \\
(\mathrm{~N}=1482)\end{array}$} & \multirow{2}{*}{$\begin{array}{c}\text { Year } 3 \\
(\mathrm{~N}=1760)\end{array}$} & \multirow{2}{*}{$\begin{array}{c}\text { Year } 4 \\
(\mathrm{~N}=1312)\end{array}$} & \multicolumn{3}{|c|}{ Meta analysis } \\
\hline & & & & & Betaplus & Q Score & Zmeta \\
\hline \multicolumn{8}{|l|}{ Homophily } \\
\hline Same gender & $.029+$ & $<.001$ & -.008 & -.022 & -.003 & 3.75 & -.13 \\
\hline Same race & $.040 *$ & $.022 \dagger$ & $.021 *$ & .006 & .019 & 1.80 & $2.73^{* *}$ \\
\hline Same role & -.009 & -.043 & .009 & $.088^{* *}$ & .020 & 10.99* & .63 \\
\hline \multicolumn{8}{|l|}{ Reputation for competence } \\
\hline Grade point average & .013 & .013 & .008 & .013 & .011 & .08 & 1.17 \\
\hline Analysis course grade & .003 & .012 & $.020^{*}$ & .011 & .013 & .95 & $1.73^{*}$ \\
\hline Database course grade & -.002 & .009 & $.017 *$ & $.018+$ & .014 & .98 & $2.12^{*}$ \\
\hline Effort on project 1 & $<-.001$ & $<.001 *$ & $<.001^{*}$ & $<.001^{*}$ & .000 & 2.43 & $2.46^{* *}$ \\
\hline Success of project 1 & .031 & .009 & -.009 & $.108^{* *}$ & .014 & 6.69 & 1.69* \\
\hline \multicolumn{8}{|l|}{ Familiarity } \\
\hline Same group & -.059 & .031 & -.029 & .025 & -.000 & 2.80 & -.02 \\
\hline \multicolumn{8}{|l|}{ i worked with j } \\
\hline Month 1 & $.032 \dagger$ & -.004 & $.018 *$ & .011 & .010 & $14.22 * *$ & $3.44 * *$ \\
\hline Month 2 & $.009+$ & $.011 *$ & .001 & $<.001$ & .004 & 2.83 & $2.29 *$ \\
\hline Month 3 & .003 & .007 & $.011^{* *}$ & $.005 t$ & .007 & 1.67 & $3.00 * *$ \\
\hline Success* same group & -.014 & .006 & $.166 * *$ & -.020 & .044 & 15.70** & 1.10 \\
\hline
\end{tabular}

$\dagger p<.10$ (one-tailed).

$* p<.05$.

$* * p<.01$. 
to work with others with whom they have worked in the past. Further, there is some suggestion of primacy and recency effects.

The analysis of the interaction term "success*same group" is al so suggestive, but there is no consistency between years. Years 2 and 3 show a positive relationship between being with someone in a successful group on project 1 and choosing them for project 2. Years 1 and 4 are negative for the same relationship. Again, the high Q score makes interpretation of these results problematic. Thus, hypothesis 4 is only partially supported-that is, people choose to work with others with whom they have had strong working relationships in the past regardless of the outcome of the project.

Taken together, the results from model 3 suggest that people choose to work with others who are the same race, who have domain-specific competence, and with whom they have worked with before. The data also suggest that being in the same group is not adequate cause for people to initiate future work ties. Rather, people choose to work with others with whom they have al ready established strong working relationships and who havea reputation for being competent and working hard.

\section{DISCUSSION}

Although extensive work has explored the effect of group composition on group processes and performance, there has been a paucity of empirical research exploring how people make choices regarding membership in work groups. The results we have presented begin to address this issue. This study enhances our understanding of the basis on which people choose work group members for new (yet to be established) groups. One of the strengths of this research is that we have simultaneously tapped three broad mechanisms that reduce uncertainty-similarity, competence, and familiarity-using multiple indicators. Our results confirm that the choice process is based on a mix of individual attributes and relational attributes. Our findings with regard to structural attributes are less clear. On one hand, being in the same group (a structural attribute) did not contribute significantly to future work group member choices. On the other hand, having worked with a person (relational attribute) in the same group (structural attribute) was a strong predictor of future work group member choices. In this domain, it appears that structural attributes are important to the extent that people are thrown together and given a chance to build a stronger relationship.

Our hypothesis that people will choose group members based on homophily was partially supported. People of the same race indicated a strong preference for working with each other independent of competence or familiarity. This may be a defensible choice given that similarity can lead to easier communication (March \& Simon, 1958) and higher levels of trust (Lincoln \& Miller, 1979), and therefore higher levels of predictability. But, groups that are demographically similar may be more isolated, less creative, and more prone to groupthink (e.g., $J$ anis, 1982). Interestingly enough, being the samegender was not an important element in choosing group members. In fact, several years (years 3 and 4) 
showed a slightly negative relationship, suggesting that people may have a slight tendency toward choosing those of the opposite gender. This finding is consistent with Lincoln and Miller's (1979) argument that gender is less important in instrumental ties and Brass's (1985) work showing that women in mixed gender work groups are perceived as having influence equal to that of men. We also examined the data to determine whether or not people were making their choices based on a preference for white male group members. The results showed no particular tendency toward wanting to work with men, zmeta $=-.90, \mathrm{p}<.82$, with whites, zmeta $=.87, \mathrm{p}<.19$, or with white males, zmeta $=.80, p<.22$. These results are inconsistent with some previous organizational research reporting that both men and women were more likely to establish instrumental ties with men (i.e., I barra, 1992). There are a number of differences between Ibarra's study and the study reported here that may explain the inconsistent results. The most important is that I barra examines existing relationships whereas we examine choice-the desire to establish a relationship. It is likely that social and organizational factors conspire to thwart people's expressed preferences for work partners. Therefore, people may have difficulty achieving a gender mix in their work groups or in their instrumental ties even if that is their preference.

Our results strongly suggest that people rely on indicators of competence when choosing future group members. In particular, people rely on thoseindicators that provide information about competence in specific areas of expertise necessary for successful completion of the task. People chose others who had been evaluated well in system analysis and design and in database design and development-all critical skills in both project 1 and project 2 . Although there was a positive relationship between grade point average for all years, the results of the meta analysis were not significant. We believe this indicates that more general measures of competence (e.g., intelligence, ability to excel in class) are less important than having the skills required for success in the project at hand. Effort and success in project 1 were also highly significant, suggesting that people like to work with others who work hard and are successful in similar projects. It is interesting to note that effort is not a measure of ability but of willingness to put in the hours on a project. It appears that, independent of competence, people value a strong work ethic in potential group members.

Although people appear to use it in choosing group members, success in project 1 is not necessarily a valid indicator of individual competence. Members of successful groups may be basking-in-reflected-glory. The basking-inreflected-gl ory model posits that people circulate information about their positive, but noninstrumental, connections as a means of garnering positive evaluations (Cialdini et al., 1976). In model 2, it appears that people want to work with others who were on successful projects, independent of the others' competence and contribution to the project. This may indicate that the halo effect of project success follows all who were a part of the project regardless of the effort put forth. 
Our results that competence matters are consistent with previous organizational studies. But, our work differs in that we never shared any information on students' competence with the study participants. Many of the studies exploring the extent to which competence leads to attraction manipulate the sharing of competency information (e.g., Berkowitz, Levy, \& Harvey, 1957; Zander \& Havelin, 1960). In our study, people are choosing group members for future projects based on people's reputation for competence. People may not actually know each other's grades or the number of hours put in on previous projects, but it is clear that a reputation for competence is developed and circulates within the organization. Further, it is an important basis on which people develop their preferences for future group members. It is interesting to note that grade point average was not a significant predictor of being chosen as a team member. This may indicate that people do not choose others based on general indicators of competence or that information on grade point average and general competence circulate less freely in these groups or are harder to assess.

Finally, we hypothesized that people would choose others with whom they were already familiar for future work groups. This hypothesis was partially supported. But, our analysis indicates that familiarity al one is not adequate to generate a future work tie. During the course of project 1, people established working relationships with others in their group. These relationships varied over time, but on average, each person had either a strong or weak tie with each other member in his or her current group. Where there were strong ties, people elected to continue those relationships in future work groups. This is consistent with Kilduff's (1990) finding that MBA students, when they look for jobs, want to work in the same companies as their friends. These data suggest that familiarity may lead to an awareness of whether or not an ongoing working relationship is effective. If a relationship is successful, then people are especially inclined to repeat it. This is consistent with our argument that people are seeking to reduce uncertainty in their choice of future group members. Although there may be better group members in the organization, people are choosing a "sure thing" rather than taking the risk of working with someone who has a work style and work ethic with which they do not have personal experience.

One of the questions that this research raises is whether or not people are making "good" choices for group members. Although we do not evaluate the composition of groups constructed by peers (groups for project 2 were created based on many criteria, including individual preferences), we can examine the nature of the choices people made. It appears that people are attempting to make choices that maximize their certainty of success. They are limiting variability (e.g., choosing homophily) and going with a "sure thing" (established working relationships). On one hand, this is a rational individual approach given the information available. On the other hand, without regulation, people using this strategy will construct groups of low diversity. As Schneider (1983) argued, organizations left to their own devices will continue to recruit similar 
others until the entire organization is homogeneous. Homogeneity can be advantageous for organizations by increasing psychological attachment to group members (Tsui, Egan, \& O'Reilly, 1992), increasing communication (Zenger \& Lawrence, 1989), and reducing turnover (J ackson, 1992; O'Reilly, Caldwell, \& Barnett, 1989; Wagner, Pfeffer, \& O'Reilly, 1984). Diversity can be advantageous for organizations by increasing flexibility and adaptiveness (Schneider, 1983; Simons, Berkowitz, \& Moyer, 1970) and by increasing innovativeness (J ackson, 1992; Schneider, 1983). Our work suggests the people will gravitate toward the creation of somewhat homogeneous, familiar groups. Therefore, organizations seeking diversity may need to create policies that ensure the devel opment of heterogeneous work groups. To reverse the trend toward homogeneity, managers may want to use peer recruiting sparingly or temper peer recommendations with the understanding that there will likely be a general bias toward similar and familiar others.

There are several limitations to this study. First, due to the preponderance of evidence in their favor, we elected to use homophily and familiarity as categories of variables in our model. Wealso included competence as an indicator of the extent to which team members rely on that which may contribute most to group success in a work setting. Although we believe that this is an appropriate set to explore, particularly given the categories overwhelming presence in the literature, there may be other categories that would add to the model. This is left for future research. Similarly, within each category, we have selected variables with which to test the importance of each category. Our measurement of possible variables is not exhaustive and much is left for future research.

Second, the participants were students in a classroom setting rather than employees in a paid work setting. Although the participants were working on real work projects in which there was task interdependence and the outcome had personal consequences for every group member, there were important ways in which this organization differed from more traditional business organizations. First, in more traditional organizations, there may be more complex power dynamics and political issues. In this study, there were group managers and, above them, faculty which formed the basis of a hierarchy. Still, these students' tenure in the organization was short. Future research in a permanent organization might uncover additional or different determinants of group member choice. Second, this group may have been more homogeneous in age, educational level, and tenure in the organization than would be expected in most permanent organizations. If age, educational level, and tenure are powerful determinants of group member choice in organizations, this study would not have identified such a pattern. Future work in more diverse organizations may add to our understanding of how these determinants interact.

Finally, we examined only one decision about whom to work with in the future. As such, our results speak primarily to the determinants of the way that people choose group members for new (yet to be established) groups. It is reasonable to assume that such one-shot decisions, such as we have studied, are not unrelated to the ongoing (possibly daily) decisions of whom to work 
with in existing groups. However, wewould expect that ongoing choices of whom to work with in existing groups are more constrained (e.g., by membership, proximity, and task) than are the one-shot decisions of whom one would like to work with in the future. Over time, the dynamics of behavior within organizations is a function of the interplay between these one-shot and ongoing choices, as well as between individuals and the larger network (see Banks \& Carley, 1996; Carley, 1991; Zeggelink, 1993). Future work needs to be done on the process of ongoing dyadic interaction and the processes, possibly chaotic, that affect such ongoing choices.

\section{REFERENCES}

Baker, F. B., \& Hubert, L. J . (1981). The analysis of social interaction data: A nonparametric technique. Sociological Methods and Research, 9, 339-361.

Banks, D. L., \& Carley, K. M. (1996). Models for network evolution. J ournal of Mathematical Sociology, 21(1-2), 173- 196.

Berger, J ., Wagner, G., \& Zelditch, M. (1985). Theoretical and metatheoretical themes in expectation states theory. In H. J . Helle \& S. N. Eisenstadt (Eds.), Perspectives on sociological theory (Vol. 2). Thousand Oaks, CA, Sage.

Berkowitz, L., Levy, B., \& Harvey, A. R. (1957). Effects of performance evaluations on group integration and motivation. Human Relations, 10, 195-208.

Blau, P. M. (1964). Exchange and power in social life New York: Wiley.

Brass, D. J . (1985). Men's and women's networks: A study of interaction patterns and influence in an organization. Academy of Management J ournal, 28, 327-343.

Brass, D. J ., \& Burkhardt, M. E. (1992). Centrality and power in organizations. In N. Nohria and R. Eccles (Eds.), Networks and organizations: Structure,form, and action. Boston, MA: Harvard Business School Press.

Byrne, D. (1961). Interpersonal attraction as a function of affiliation need anda ttitude similarity. Human Relations, 14, 283-289.

Cable, D. M., \& J udge, T. A. (1996). Person-organization fit, job choice decisions, and organizational entry. Organizational Behavior and Human Decision Processes, 67(3), 294-311.

Carley, K. (1990). Group stability: A socio-cognitive approach. In E. Lawler, B. Markovsky, C. Ridgeway, \& H. Walker (Eds.), Advances in group processes: Theory and research (Vol. VII, pp. 1-40) Greenwich, CT: J Al.

Carley, K. (1991), A theory of group stability. American Sociological Review, 56(3), 331-354.

Carley, K. M. (1999), On the evolution of social and organizational networks. Research in the Sociology of Organizations, 16, 3-30.

Carley, K. M., \& Krackhardt, D. (1996). Cognitive inconsistencies and non-symmetric friendship. Social Networks, 18: 1-27.

Cialdini, R. B., Borden, R. J ., Thorne, A., Walker, M. R., Freeman, S., \& Sloan, L. R. (1976). Basking in reflected glory: Three (football) field studies.J ournal of Personality and Social Psychology, 34, 366- 375.

Etzioni, A. (1964). Modern organizations. Englewood Cliffs, NJ : Prentice Hall.

Festinger, L. (1953). Group attraction and membership. In D. Cartwright \& A. Zander (Eds.), Group dynamics: Research and theory. Evanston, IL: Row, Peterson.

Gilchrist, J . C. (1952). The formation of social groups under conditions of success and failure. J ournal of Abnormal and Social Psychology, 47, 174- 187.

Goodman, P. S., \& Leyden, D. P. (1991). Familiarity and group productivity. J ournal of Applied Psychology, 76, 578-586. 
Hedges, L. V., \& Olkin, I. (1985). Statistical methods for meta-analysis. New York: Academic Press.

Hollenbeck, J. R., Ilgen, D. R., Sego, D. J ., Hedlund, J ., Major, D. A., \& Phillips, J . (1995). The multi-level theory of team decision making: Decision performance in teams incorporating distributed expertise. J ournal of Applied Psychology, 80, 292-316.

Hubert, L. J . (1987). Assignment methods in combinatorial data analysis. New York: Dekker.

Hubert, L. J ., \& Golledge, R. G. (1981). A heuristic method for the comparison of related structures. J ournal of Mathematical Psychology, 23, 214-226.

Hubert, L., \& Schultz. J . (1976). Quadratic assignment as a general data analysis strategy. British J ournal of Mathematical Psychology, 29, 190-241.

Ibarra, H. (1992) Homophily and differential returns: Sex differences in network structure and access in an advertising firm. Administrative Science Quarterly, 37, 422- 447.

J ackson, S. E. (1992). Team composition in organizational settings: I ssues in managing an increasingly diverse work force. In Worshel, Wood, \& Simpson (Eds.), Group process and productivity. Newbury Park, CA: Sage.

J anis, I. L. (1982). Groupthink: Psychol ogical studies of policy decisions and fiascoes. Boston, MA: Houghton Mifflin.

J ehn, K., Northcraft, G., \& Neale, M. (1997). Opening Pandora's box: A field study of diversity, conflict, and performance in work groups. Working Paper, Wharton School, University of Pennsylvania.

J udge, G. G., Griffitsh, W. E., Carter Hill, R., Lutkepohl, H., \& Lee, T. (1990). The theory and practice of econometrics. New York: Wiley.

Kanter, R. M. (1977). Men and women of the corporation. New York: Basic Books.

Kaufer, D. S., \& Carley, K. M., (1993). Communication at a distance: The effect of print on sociocultural organization and change. Hillsdale, $\mathrm{NJ}$ : Lawrence Erlbaum Associates.

Kenny, D. A., Bond, C. F., J r., Mohr, C., \& Horn, E. M. (1996). Do we know how much people like one another? J ournal of Personality and Social Psychology, 71, 928-936.

Kilduff, M. (1990). The interpersonal structure of decision making: A social comparison approach to organizational choice. Organizational Behavior and Human Decision Processes, 47, 270- 288.

Kilduff, M., \& Krackhardt, D. (1994). Bringing the individual back in: A structural analysis of the internal market for reputation in organizations.Academy of Management J ournal, 37, 87- 108.

Krackhardt, D. (1987). QAP partialling as a test of spuriousness, Social Networks, 9, 171-186.

Krackhardt, D. (1988). Predicting with networks: Nonparametric multiple regression analysis of dyadic data. Social Networks, 10, 359-381.

Krackhardt, D. (1992). The strength of strong ties: The importance of philos in organizations. In N. N ohria and R. Eccles (Eds.), Networks and organizations: Structure, form, and action. Boston, MA: Harvard Business School Press.

Krackhardt, D. (1993). MRQAP: Analytic versus permutation solutions. Working paper, Carnegie Mellon University.

Krackhardt, D., \& Kilduff, M. (1999) Whether close or far: Perceptions of balance in friendship networks in organizations. J ournal of Personality and Social Psychology, 76, 770-782.

Lazarsfeld, P. F., \& Merton, R. K. (1954). Friendship as a social process: A substantive and methodological analysis. In M. Berger, T. Abel, \& C. H. Page (Eds.), Freedom and control in modern society. New York: Van Nostrand.

Laumann, E. O., \& Pappi, F. U. (1976). Networks of collective action: A perspective on community influence systems. New York: Academic Press.

Levine, J. M., \& Moreland, R. L. (1991). Progress in small group research. Annual Review of Psychology, 41, 585-634.

Lincoln, J. R. (1984). Analyzing relations in dyads: Problems, models, and an application to interorganizational research. Sociological Methods and Research, 3, 45- 76. 
Lincoln, J . R., \& Miller, J . (1979). Work and friendship ties in organizations: A comparativeanalysis of relational networks. Administrative Science Quarterly, 24, 181- 199.

Lott, A. J ., \& Lott, B. E. (1964). Group cohesiveness as interpersonal attraction: A review of relationships with antecedent and consequent variables. Psychological Bulletin, 64, 259-309.

March, J . G., \& Simon, H. A. (1958). Organizations. New York: Wiley.

McPherson, J . M., \& Smith-Lovin, L. (1987). Homophily in voluntary organizations: Status distance and the composition of face-to-face groups. American Sociological Review, 52, 370- 79.

McPherson, J . M., \& Smith-Lovin, L. (1986). Sex segregation in voluntary associations. American Sociological Review, 51, 61-79.

Mizruchi, M., \& Galaskiewicz, J . (1994). Networks of organizations. In S. Wasserman \& J . Galaskiewicz (Eds.), Advances in social network analysis (pp. 230-254). Thousand Oaks, CA: Sage.

Moreland, R. L., \& Levine, J . M. (1994). The composition of small groups. In E. Lawler, B. Markovsky, C. Ridgeway, and H. Walker (Eds.), Advances in group processes (Vol. 9). Greenwich, CT:J Al .

Murphy, K. R., \& Cleveland, J . N. (1991). Performance appraisal: An organizational perspective. Needham Heights, MA: Allyn \& Bacon.

O' Reilly, C. A., Caldwell, D. F., \& Barnett, W. P. (1989). Work group demography, social integration, and turnover. Administrative Science Quarterly, 34, 21-37.

O’Reilly, C. A., Williams, K., \& Barsade, S. (1997). Group demography and innovation: Does diversity help? In E. Mannix and M. Neale (Eds.), Research in the management of groups and teams (Vol. 1). Greenwich, CT: J Al.

Pelled, L., Eisenhardt, K., \& Xin, K. (1997). Demographic diversity in work groups: An empirical assessment of linkages to intragroup conflict and performance. Working Paper, School of Business, University of Southern California.

Perrow, C. (1972). Review of D. Neuhauser's. The relationship between administrative activities and hospital performance. Administrative Science Quarterly, 17, 419-421.

Pfeffer, J ., Salancik, G. R., \& Leblebici, H. (1976). The effect of uncertainty on the use of social influence on organizational decision making. Administrative Science Quarterly, 21, 227-245.

Proctor, C. H. (1975). Graph sampling compared to conventional sampling. In P. W. Holland \& S. Leinhardt, (Eds.), Perspectives on social network research (pp. 301-318). New York: Academic Press.

Rhodes, W. S., Newman, L. S., \& Ruble, D. N. (1990). In E. T. Higgins and R. M. Sorrentino (Eds.), Motivation and cognition. New York: Guilford Press.

Ridgeway, C. L. (1984). Dominance, performance, and status in groups: A theoretical analysis. In E. J . Lawler (Ed.), Advances in group processes (Vol. 1). Greenwich CT: J AI.

Schneider, B. (1983). Interactional psychology and organizational behavior. In L. L. Cummings and B. M. Staw (Eds.), Research in organizational behavior (Vol. 5). Greenwich, CT: J AI.

Schott, T. (1987). Interpersonal influence in science: Mathematicians in Denmark and Isreal. Social Networks, 9, 351-374.

Simons, H. W., Berkowitz, N. N., \& Moyer, R.J . (1970). Similarity, credibility, and attitude change: A review and a theory. Psychological Bulletin, 73, 1-15.

Spence, A. M. (1973). J ob market signaling. Quarterly J ournal of Economics, 90, 225-243.

Stouffer, S. A., Suchman, E. A., De Vinney, L. C., Star, S. A., \& Williams, R. M., J r. (1949). The American soldier: Adjustment during Army life (Vol. 1). Princeton, NJ : Princeton University Press.

Thibaut, J . W., \& Kelley, H. H. (1959). The social psychology of groups. New York: Wiley.

Thompson, J . D. (1967). Organizations in action. New York: McGraw-Hill.

Tsui, A. S. (1984). A role set analysis of managerial reputation. Organizational Behavior and Human Performance, 34, 64-96.

Tsui, A. S., Egan, T. D., \& O'Reilly, C. A. (1992). Being different: Relational demography and organizational attachment. Administrative Science Quarterly, 37, 549-579. 
Tsui, A. S., \& O'Reilly, C. A. (1989). Beyond simple demographic effects: Theimportance of relational demography in superior-subordinate dyads. Academy of Management J ournal, 32, 402-423.

Wagner, W. G., Pfeffer, J ., \& O'Reilly, C. A. (1984). Organizational demography and turnover in top-management groups. Administrative Science Quarterly, 29, 74- 92.

Wasserman, S., \& Faust, K. (1994). Social network analysis: Methods \& applicatons. Cambridge, UK: Cambridge Univ. Press.

Williams, K. Y., \& O'Reilly, C. A. (1998). Demography and diversity in organizations: A review of 40 years of research. In B. Staw \& L. Cummings (Eds.), Research in organizational behavior (Vol. 20). Greenwich, CT: J Al.

Wolf, F. M. (1986). Meta-analysis: Quantitative methods for research synthesis. Newbury Park, CT: Sage.

Zander, A., \& Havelin, H. H. (1960). Social comparison and interpersonal attraction. Human Relations, 13, 21- 32.

Zeggelink, E. (1993). Strangers into friends: The evolution of friendship networks using an individual oriented modeling approach. Amsterdam: Thesis Publishers.

Zenger, T., \& Lawrence, B. (1989). Organizational demography: The differential effects of age and tenure distributions on technical communication. Academy of ManagementJ ournal, 32, 353-376.

Received October 8, 1998 